\title{
Pediatric neurosurgical workforce, access to care, equipment and training needs worldwide
}

\author{
Michael C. Dewan, MD, MSCI, ${ }^{1}$ Ronnie E. Baticulon, MD, ${ }^{2}$ Abbas Rattani, MBe, ${ }^{3}$ \\ James M. Johnston Jr., MD, ${ }^{4}$ Benjamin C. Warf, MD, ${ }^{5}$ and William Harkness, $\mathrm{MBChB}^{6}$ \\ 1Department of Neurological Surgery, Vanderbilt University Medical Center, Nashville, Tennessee; 2Department of Neurosurgery, \\ University of the Philippines College of Medicine, Mabani, Ermita, Manila, Philippines; ${ }^{3}$ Stritch School of Medicine, Loyola \\ University Chicago, Maywood, Illinois; ${ }^{4}$ Department of Neurosurgery, University of Alabama at Birmingham, Alabama; \\ ${ }^{5}$ Department of Neurological Surgery, Boston Children's Hospital, Boston, Massachusetts; and ${ }^{6}$ Department of Neurosciences, \\ Institute for Child Health, London, United Kingdom
}

OBJECTIVE The presence and capability of existing pediatric neurosurgical care worldwide is unknown. The objective of this study was to solicit the expertise of specialists to quantify the geographic representation of pediatric neurosurgeons, access to specialist care, and equipment and training needs globally.

METHODS A mixed-question survey was sent to surgeon members of several international neurosurgical and general pediatric surgical societies via a web-based platform. Respondents answered questions on 5 categories: surgeon demographics and training, hospital and practice details, surgical workforce and access to neurosurgical care, training and equipment needs, and desire for international collaboration. Responses were anonymized and analyzed using Stata software.

RESULTS A total of 459 surgeons from 76 countries responded. Pediatric neurosurgeons in high-income and uppermiddle-income countries underwent formal pediatric training at a greater rate than surgeons in low- and lower-middleincome countries (89.5\% vs 54.4\%). There are an estimated 2297 pediatric neurosurgeons in practice globally, with $85.6 \%$ operating in high-income and upper-middle-income countries. In low- and lower-middle-income countries, roughly 330 pediatric neurosurgeons care for a total child population of 1.2 billion. In low-income countries in Africa, the density of pediatric neurosurgeons is roughly 1 per 30 million children. A higher proportion of patients in low- and lower-middleincome countries must travel $>2$ hours to seek emergency neurosurgical care, relative to high-income countries $(75.6 \%$ vs $33.6 \%, p<0.001$ ). Vast basic and essential training and equipment needs exist, particularly low- and lower-middleincome countries within Africa, South America, the Eastern Mediterranean, and South-East Asia. Eighty-nine percent of respondents demonstrated an interest in international collaboration for the purposes of pediatric neurosurgical capacity building.

CONCLUSIONS Wide disparity in the access to pediatric neurosurgical care exists globally. In low- and lower-middleincome countries, wherein there exists the greatest burden of pediatric neurosurgical disease, there is a grossly insufficient presence of capable providers and equipped facilities. Neurosurgeons across income groups and geographic regions share a desire for collaboration and partnership.

https://thejns.org/doi/abs/10.3171/2018.7.FOCUS18272

KEYWORDS global; access to care; pediatric neurosurgery; survey; workforce; worldwide

$\mathrm{M}$ ORE than two-thirds of the global population lacks access to appropriate surgical care, and an estimated 140 million necessary surgical procedures are left undone, resulting in extreme economic costs and profound disability and death. ${ }^{18}$ An estimated 22.6 million patients have neurological disorders warranting the expertise of a neurosurgeon, with nearly 14 million requiring surgical intervention. ${ }^{8}$ The proportion of these figures represented by children is unknown. However, the vast majority of the unmet need is in low- and middle-

ABBREVIATIONS AFR = African region; AMR-LA = Latin American region; AMR-US/C = North American region; EMR = Eastern Mediterranean region; EUR = European region; HIC = high-income country; LIC = low-income country; IMIC = lower-middle-income country; LMICs = low- and middle-income countries; SEAR = South-East Asia region; uMIC = upper-middle-income country; WBIG = World Bank income group; WPR = Western Pacific region. ACCOMPANYING EDITORIAL DOI: 10.3171/2018.7.FOCUS18364.

SUBMITTED May 30, 2018. ACCEPTED July 12, 2018.

INCLUDE WHEN CITING DOI: 10.3171/2018.7.FOCUS18272. 
income countries (LMICs), where children make up a disproportionately larger fraction of the population. ${ }^{1}$

No formal global registry of pediatric neurosurgeons exists, and there is no consensus on the number of pediatric neurosurgeons capable of addressing the burden of neurosurgical disease in children. Moreover, the ability of regional populations in LMICs to access existing neurosurgical care is unknown but is believed to be limited. ${ }^{17,18}$ To enact targeted interventions and maximize capacity building in those areas with the greatest need, ${ }^{19}$ characterization of the pediatric neurosurgical workforce in a geographic manner is imperative. Additionally, defining the equipment and training needs of existing surgical specialists will inform programs of education and training to strengthen and increase surgical capacity. While a potential means of determining this information may include country-by-country hospital surveys or data extraction from Ministries of Health and incorporated health agencies, such an endeavor is costly, time-consuming, and itself imperfect. Instead, in this epidemiological survey, we solicit the expertise of surgical and neurosurgical specialists worldwide to quantify the geographic representation of pediatric neurosurgeons, access to specialist care, and equipment and training needs globally.

\section{Methods}

An initial invitation email was sent July 9, 2017, to members of the International Society for Pediatric Neurosurgery (ISPN), the European Society for Pediatric Neurosurgery (ESPN), the Global Initiative for Children's Surgery (GICS), and the World Federation of Associations of Pediatric Surgeons (WOFAPS). Several other surgical societies were contacted for participation, including the College of Surgeons of East, Central and Southern Africa; the Asian Australasian Society of Neurosurgeons; the Cotinental African Association of Neurosurgical Societies; and the Federación Latinoamericana de Sociedades de Neurocirugía. However, members of these societies were not sent email invitations due to privacy agreements within their membership code, or because society representatives did not facilitate solicitation of their members electronically. For those receiving an email, surgeons were directed to an approximately 15-minute survey housed within the REDCap (Research Electronic Data Capture) data manager at Vanderbilt University. ${ }^{12}$ Two reminder emails were sent, and answers were collected until August 20, 2017.

Survey questions (Supplement) were designed to capture country-specific information about the current status of pediatric neurosurgery within the respondent's home country, as well as the future outlook for surgical delivery. The questions relevant to this study were organized into 5 categories: surgeon demographics and training, hospital and practice details, surgical workforce and access to neurosurgical care, training and equipment needs, and the desire for international collaboration. With permission, personal information, including name and email address, was solicited for professional networking if the respondent demonstrated interest.

Responses were anonymized and exported directly to
Stata software (version 14, StataCorp) for analysis. Data were analyzed using nonparametric statistical methods and reported as mean (confidence interval) and compared using the Mann-Whitney U-test (2 comparators) or Kruskal-Wallis test ( $>2$ comparators). Dichotomous data were compared using the chi-square test; $\mathrm{p}<0.05$ was considered statistically significant.

Country-specific population data for the year 2016 were obtained from World Bank Open Data (https://data. worldbank.org). The database estimates the total population of people ages 0 to 14 years in each country, and this figure was used to represent the child population in computing pediatric neurosurgeon density in each country, region, and income group. Due to the paucity of pediatric neurosurgeons in LMICs, pediatric neurosurgeon density is expressed per 1 million children, rather than the customary per 100,000 population.

For countries not represented by at least 1 respondent, the estimated number of pediatric neurosurgeons residing therein was imputed at the country level as follows. Using data from existing respondents, a pediatric neurosurgeon density (number of pediatric neurosurgeons per 1 million children) was calculated for each combination of WHO region and World Bank income group (WBIG; 7 regions and 4 income groups for a total of 28 theoretical combinations). The number of neurosurgeons in-country reported by respondents was divided by the country's child population to obtain a density value. Next, this value from each respondent was averaged across respondents within each WHO region and WBIG combination. For those countries without a respondent, the child population was multiplied by the density correlating to the WHO region and WBIG combination, and an estimate for the number of pediatric neurosurgeons was generated.

The obtained and imputed surgeon densities were exported to Tableau Public (v10.4, Tableau Software) to generate a gradient world map that illustrates survey results. Additional figures were generated using the same software to highlight ease of access to pediatric neurosurgical care, perceived adequacy of specialists, and training and equipment needs across regions and income groups.

\section{Results}

\section{Study Sample Characteristics}

Answers were obtained from 459 surgeons in 76 countries, including 369 neurosurgeons and 319 pediatric neurosurgeons (Table 1). Among nonneurosurgeons, neurosurgical conditions accounted for an average of $14 \%$ of their practice and volume. Forty-three percent of general surgeons reported routinely providing emergency neurosurgical care for children. Nonneurosurgical conditions account for an average of only $8 \%$ of the clinical volume of neurosurgeons worldwide. Across all regions, neurosurgeons reported performing an average of 216 cases per year (median 200), while the mean case volume for general pediatric surgeons was significantly greater at 421 cases per year (median 300) ( $p<0.001$ ). On a 100-point scale, surgeons were asked how busy they believe their surgical practice is, with 0 representing "not at all busy," and 100 representing "extremely busy, overworked." Neu- 
TABLE 1. Respondent characteristics

\begin{tabular}{lc}
\hline & No. of Respondents $(\%)$ \\
\hline Surgeon respondents & $459(100)$ \\
\hline Neurosurgeons & $369(80.4)$ \\
\hline Pediatric neurosurgeons & $319(69.5)$ \\
\hline General pediatric surgeons & $90(19.6)$ \\
\hline Neurosurgeon demographics $(\mathrm{n}=369)$ & $5(1.4)$ \\
\hline LIC & $88(23.9)$ \\
\hline IMIC & $63(17.1)$ \\
\hline UMIC & $213(57.7)$ \\
\hline HIC & $13(3.5)$ \\
\hline AFR & $40(10.8)$ \\
\hline AMR-LA & $57(15.5)$ \\
\hline AMR-US/C & $25(6.8)$ \\
\hline EMR & $90(24.4)$ \\
\hline EUR & $75(20.3)$ \\
\hline SEAR & $69(18.7)$ \\
\hline WPR &
\end{tabular}

rosurgeons and general surgeons reported a similar mean workload: $72 / 100$ vs $73 / 100(p=0.66$; Table 2$)$.

\section{Training and Workplace-Pediatric Neurosurgery}

The mean number of years in practice among neurosurgeons was 16.6 years (median 15.5 years). Ninetythree percent of respondents self-identifying as neurosurgeons reported having undergone formal, graduate-level neurosurgical training, while $4.6 \%$ reported only casual training by observing a formally trained neurosurgeon. General neurosurgeons (those not self-identifying as pediatric-specific neurosurgeons) report that an average of $30.1 \% \pm 2.9 \%$ of their practice involves the evaluation or treatment of pediatric patients.

Among self-identifying pediatric neurosurgeons, $83 \%$ described having undergone formal pediatric neurosurgery training above and beyond their basic neurosurgical training. A difference in formal pediatric neurosurgical training was observed across WBIGs: $89.5 \%$ of respondents from high-income (HICs) or upper-middle-income countries (uMICs) received formal training, relative to only $54.4 \%$ from low-income countries (LICs) or lower-middle-income countries $(\mathrm{lMICs})(\mathrm{p}<0.001)$. There was also a difference across WHO regions: between the North American region (AMR-US/C) and European region (EUR), 89.7\% obtained formal pediatric neurosurgical training, compared with only $64.9 \%$ for surgeons in the South-East Asia (SEAR) and Western Pacific (WPR) regions ( $\mathrm{p}<0.001)$. Of note, 94.8\% from the Latin American region (AMR-LA) and all 5 pediatric neurosurgeons responding from the African region (AFR) described receiving formal pediatric neurosurgical training. The vast majority of respondents (90\%) reported practicing primarily in a tertiary or quaternary referral center, a feature that did not differ across WHO regions or WBIGs $(\mathrm{p}>0.05$; Table 2$)$.

\section{Pediatric Neurosurgical Workforce}

The 76 countries from which survey respondents estimated the number of practicing pediatric neurosurgeons in their country account for $81 \%$ of the world population.

TABLE 2. Summary of training, volume, and access by WHO region and WBIG

\begin{tabular}{|c|c|c|c|c|c|c|}
\hline & $\begin{array}{l}\text { No. (\%) of PNS } \\
\text { Respondents Who } \\
\text { Received Formal } \\
\text { PNS Training* }\end{array}$ & $\begin{array}{c}\text { Mean }(95 \% \mathrm{Cl}) \\
\text { Estimated No. of } \\
\text { Cases Performed } \\
\text { Annually }\end{array}$ & $\begin{array}{c}\text { Mean } \\
(95 \% \mathrm{Cl}) \\
\text { Perceived } \\
\text { Workload† }\end{array}$ & $\begin{array}{c}\text { Mean } \%(95 \% \mathrm{Cl}) \\
\text { of Pts Traveling } \\
>2 \text { Hrs for } \\
\text { Emergency Care }\end{array}$ & $\begin{array}{c}\text { Mean \% }(95 \% \mathrm{Cl}) \\
\text { No. of Pts Traveling } \\
>2 \text { Hrs for } \\
\text { Elective Care }\end{array}$ & $\begin{array}{c}\text { No. (\%) of } \\
\text { Respondents } \\
\text { Agreeing w/ Survey } \\
\text { Statement‡ }\end{array}$ \\
\hline \multicolumn{7}{|l|}{ WBIG } \\
\hline LIC & $2 / 2(100)$ & $383(184-583)$ & $78(65-90)$ & $76(49-100)$ & $92(85-99)$ & $0 / 5(0)$ \\
\hline IMIC & $29 / 55$ (53) & $256(214-297)$ & $72(67-76)$ & $63(58-68)$ & $72(68-77)$ & $18 / 88(20)$ \\
\hline UMIC & 49/56 (87) & $212(173-250)$ & $76(72-80)$ & $44(38-51)$ & $62(56-68)$ & $31 / 62(50)$ \\
\hline $\mathrm{HIC}$ & $165 / 183(90)$ & $197(181-214)$ & $71(69-74)$ & $34(30-37)$ & $49(45-52)$ & $165 / 213(77)$ \\
\hline \multicolumn{7}{|l|}{ WHO region } \\
\hline AFR & $5 / 5(100)$ & $313(189-438)$ & $75(70-83)$ & $60(38-81)$ & 70 (48-91) & $1 / 13(8)$ \\
\hline AMR-LA & $37 / 39$ (95) & 198 (156-241) & $78(74-83)$ & $41(33-49)$ & $57(50-64)$ & $27 / 40(68)$ \\
\hline AMR-US/C & $53 / 57(93)$ & $200(183-218)$ & $67(61-72)$ & $34(28-40)$ & $48(42-53)$ & $48 / 57(84)$ \\
\hline EMR & $18 / 19(95)$ & $187(129-245)$ & $76(67-85)$ & $57(48-67)$ & $72(64-79)$ & $7 / 25(28)$ \\
\hline EUR & $69 / 79$ (87) & $243(215-271)$ & $76(73-79)$ & $28(22-33)$ & $47(41-52)$ & $77 / 90(86)$ \\
\hline SEAR & $22 / 47$ (47) & $276(230-322)$ & $73(68-77)$ & $64(58-69)$ & $73(69-78)$ & $14 / 75(19)$ \\
\hline WPR & $41 / 50(82)$ & $137(107-168)$ & $66(61-71)$ & $42(35-49)$ & $55(48-62)$ & $40 / 68(59)$ \\
\hline
\end{tabular}

PNS = pediatric neurosurgery.

${ }^{*}$ Not all respondents answered this question.

$\dagger 0=$ not at all busy; $100=$ extremely busy, overworked.

$\ddagger$ The survey statement is "There are enough pediatric neurosurgeons in my country." The percentages represent those who answered "strongly agree" or "agree somewhat." Not all respondents answered this question. 


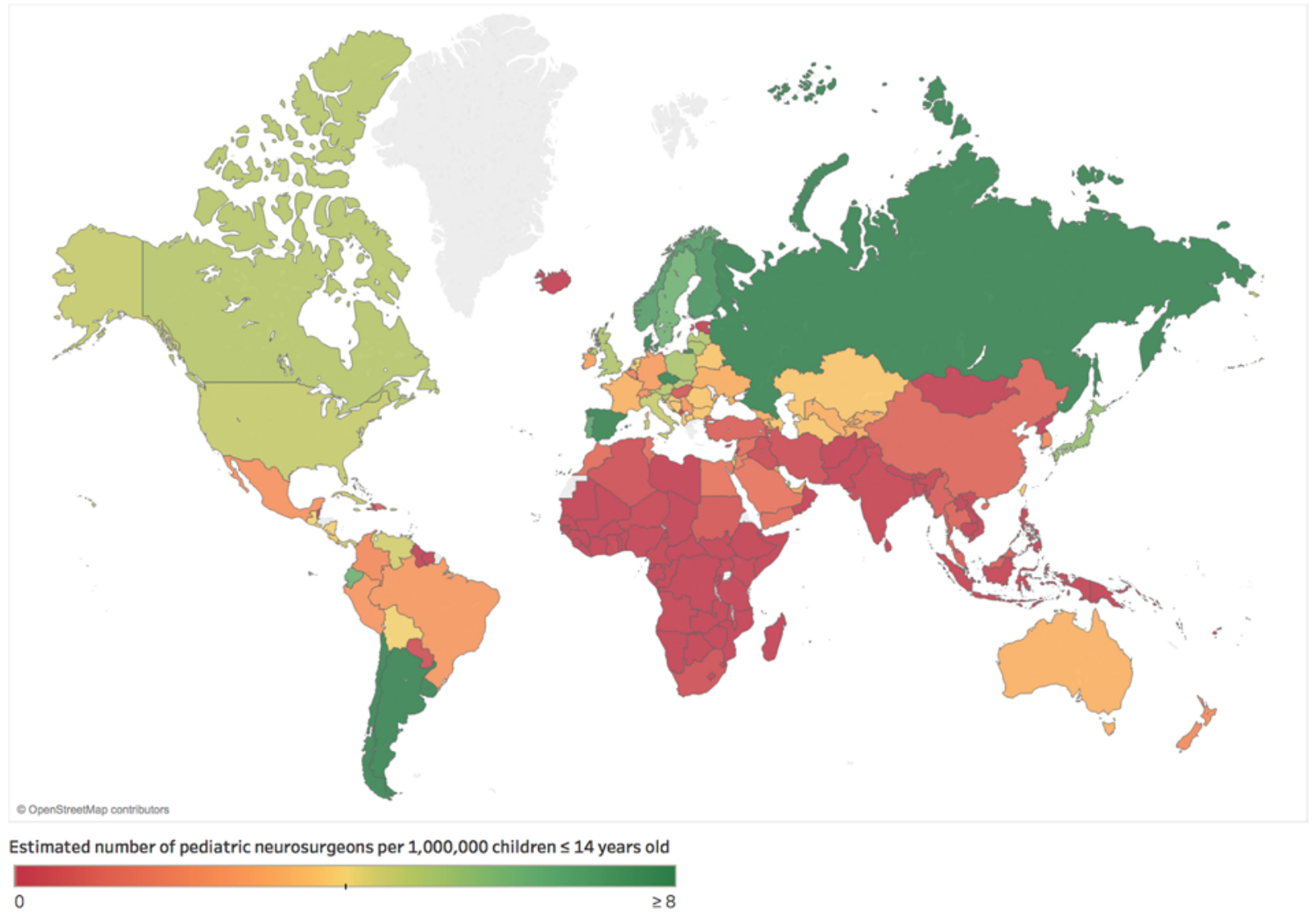

FIG. 1. Pediatric neurosurgeon density by country. The color-gradient world map illustrates the estimated number of pediatric neurosurgeons per 1 million children $\leq 14$ years. The right end of the gradient represents 8 or more pediatric neurosurgeons per million children; the midpoint is set at 4 neurosurgeons. CC BY-SA. https://creativecommons.org/licenses/by-sa/2.0/legalcode.

Based on these results, we estimated that there are 2012 pediatric neurosurgeons spread across these 76 countries. For the remaining $19 \%$ of the global population an additional 285 neurosurgeons-primarily from small and/ or lower income regions-were imputed as outlined in Methods. Among the 2297 pediatric neurosurgeons estimated, 1967 (85.6\%) operate in HICs or uMICs; 325 reside in IMICs and only 5 pediatric neurosurgeons were identified from the 30 LICs. Large differences also exist across WHO regions: 1038 pediatric neurosurgeons work in the European or North American regions, while only 89 work throughout SEAR, and only 24 practice in the entire AFR. The highest density of pediatric neurosurgeons was found among HICs in North America, Latin America, Europe and the Western Pacific, where there is approximately 1 pediatric neurosurgeon for every 250,000 children. In contrast, in LICs in the AFR, there is an estimated 1 pediatric neurosurgeon for every 30 million children. The disparity in pediatric neurosurgical presence per million children is evident across and within WHO regions (Fig. 1).

\section{Proximity to Neurosurgical Care}

Surgeons were asked to estimate the proportion of patients needing to travel more than 2 hours to seek both emergency and elective neurosurgical care. In LICs, more than three-quarters of patients $(75.6 \%)$ travel more than 2 hours to reach emergency neurosurgical care, compared with one-third of patients $(33.6 \%)$ in HICs $(\mathrm{p}<0.001)$ (Fig. 2 ). In the AFR and SEAR, $60 \%$ and $64 \%$ of patients travel more than 2 hours, respectively, much greater than that observed in EUR $(28 \%)$ and AMR-US/C $(34 \%)(\mathrm{p}<0.001)$ (Table 2, Fig. 3).

Similar disparity in access to elective neurosurgical care was also observed. More than $90 \%$ of patients in LICs must travel more than 2 hours to seek elective care, compared with less than half $(49 \%)$ in HICs (p < 0.001). The vast majority of patients in the AFR (70\%), SEAR (73\%), and Eastern Mediterranean (EMR) region (72\%) traveled more than 2 hours for elective neurosurgical care - a greater proportion of patients than in the AMR-US/C $(48 \%)$ and EUR $(47 \%)(\mathrm{p}<0.001)$. A direct relationship exists between income designation and the proportion of surgeon respondents in agreement that the number of pediatric neurosurgeon in their country is adequate (Table 2, Fig. 2).

\section{Training and Equipment Needs}

Across WHO regions and WBIGs, few $(<25 \%)$ reported a need for further training in shunt insertion for hydrocephalus or trauma-related neurosurgery (Fig. 4, Table S1). There was substantial interest in further training in endoscopy and epilepsy surgery, respectively, in AFR 


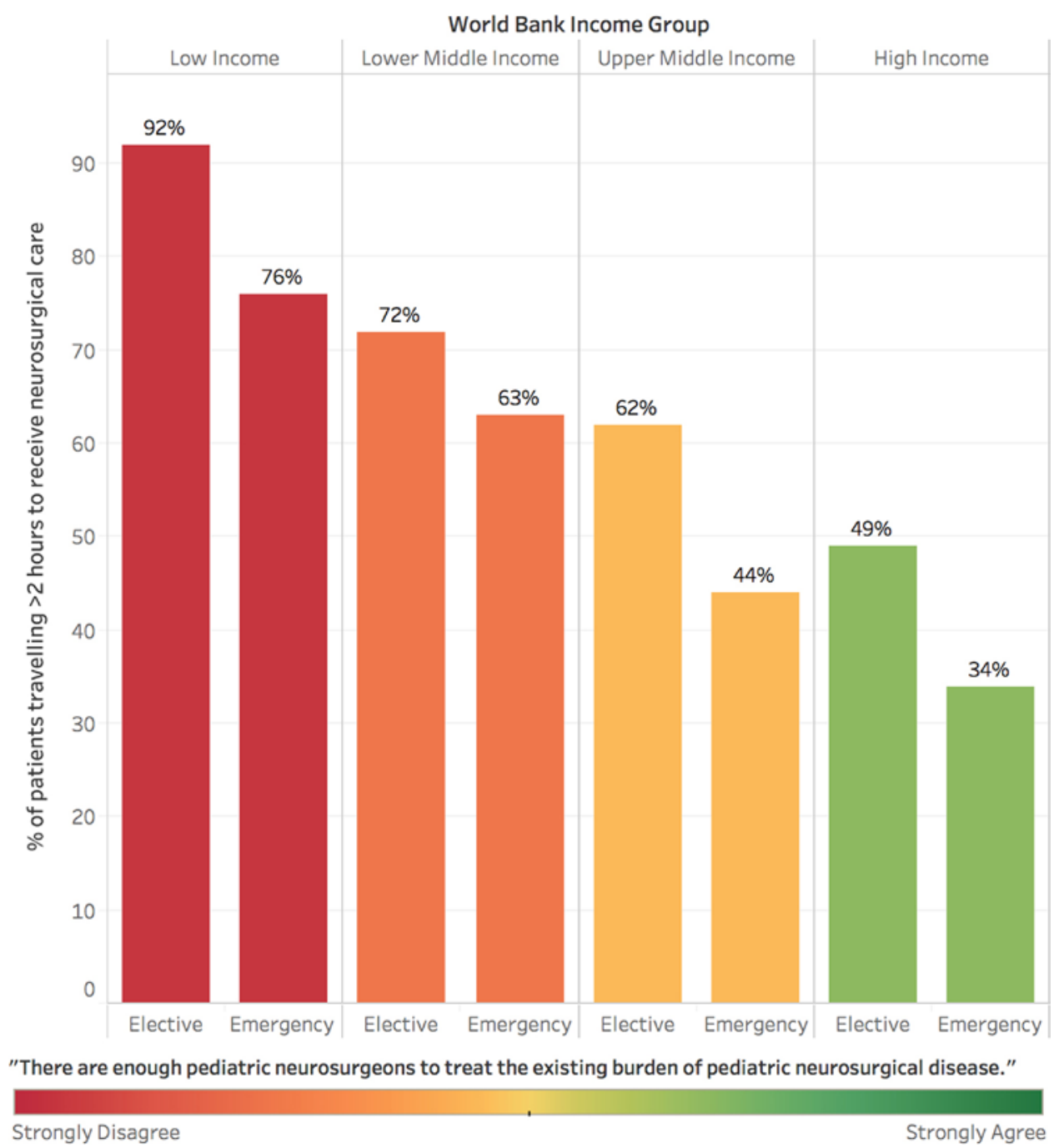

FIG. 2. Pediatric neurosurgery workforce and distance to care. The height of the vertical bars represents the proportion of patients who travel $>2$ hours to seek emergency or elective neurosurgical care for each WBIG. The color represents the respondents' perceived adequacy of pediatric neurosurgeons to meet the existing burden of disease in their country.

(69\% and 77\%), EMR (52\% and 76\%), and LICs (60\% and $100 \%)$. The management of vascular disorders was also an expressed area of deficiency in these same regions $(62 \%-$ $80 \%$ ). Spinal instrumentation and craniofacial reconstruction were commonly listed as modest areas of need across most regions (19\%-52\%) and income groups (29\%-40\%). The need for further training in spinal dysraphism management was listed in greater frequency among respondents from HICs and uMICs (22\% and 24\%) than those from LICs and $1 \mathrm{MICs}(0 \%$ and $18 \%)$.

Respondents were also asked to list the primary equipment needs at their center (Fig. 5, Table S2). Among respondents from LICs, $60 \%$ reported needing a drill, and $80 \%$ needed a microscope and microinstruments. Between $25 \%$ and $33 \%$ of respondents across all non-North American regions described a need for an endoscope, except for Africa where the figure approached 50\%. Regardless of WBIG or WHO region, imaging equipment was not considered among the primary needs of most respondent neurosurgeons. Spinal implants, shunt hardware, and microinstruments were variably listed as primary necessities across WHO regions.

\section{International Partnership}

Finally, surgeons were queried about their interest in establishing formal partnerships with surgeons in other countries for mutual sharing of information, education, and resources. Across all WBIGs and WHO regions, 89\% of all respondents indicated a desire for such collaboration. Among respondents in LICs and 1MICs, 99\% were interested in partnerships, while $97 \%$ and $82 \%$ from uMICs and HICs, respectively, indicated interest. One hundred percent of respondents from Africa indicated an interest, while $92 \%$ and $99 \%$ of respondents from Latin America and South-East Asia, respectively, expressed enthusiasm for international collaboration. Eighty-four percent of North American surgeons and 88\% of European surgeons confirmed a desire to participate in a form of partnership 


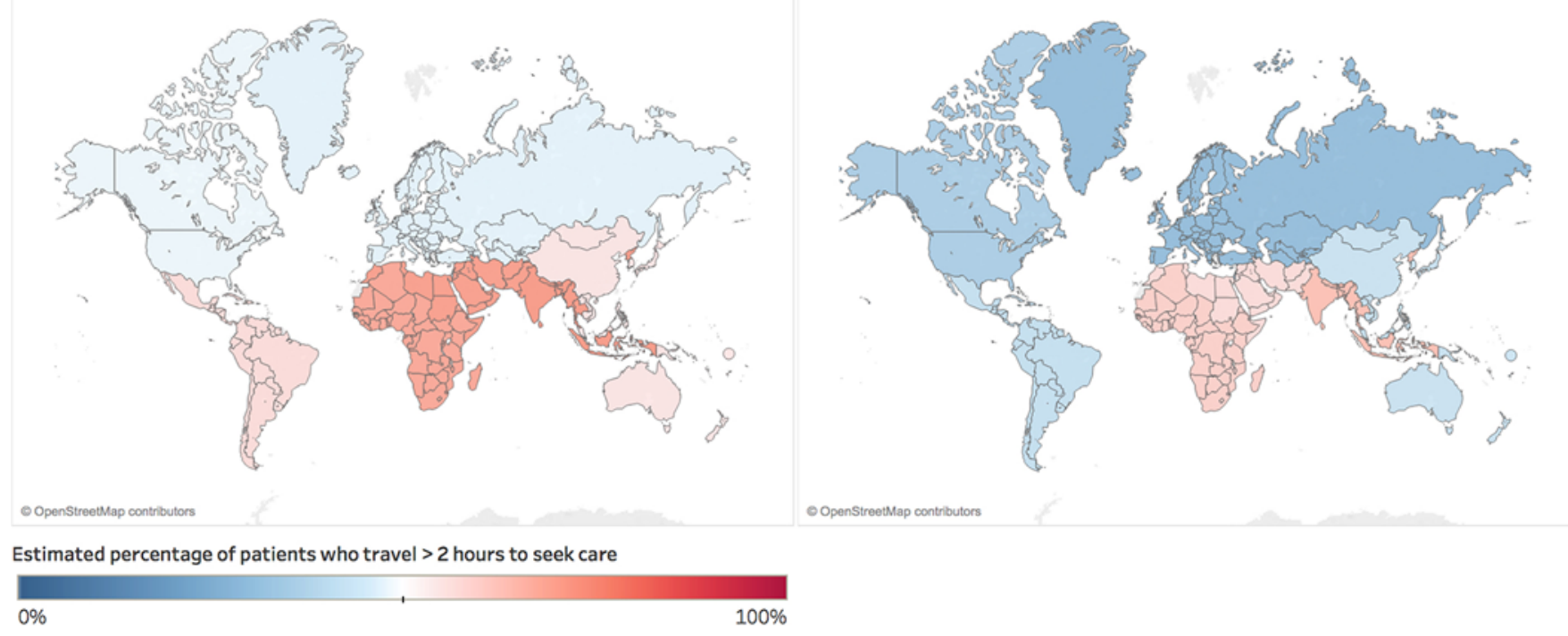

FIG. 3. Regional comparison of distance to pediatric neurosurgical care. The color-gradient map illustrates the proportion of patients traveling > 2 hours to seek emergency or elective neurosurgical care. The blue-red midpoint is set at $50 \%$; darker red regions represent a higher proportion. CC BY-SA. https://creativecommons.org/licenses/by-sa/2.0/legalcode.

network. Surgeons were not asked if they were currently or previously engaged in any form of transnational neurosurgical partnership but were given the opportunity to submit their contact information if they would like to be involved in partnerships in the future.

\section{Discussion}

This international survey of neurosurgeons and other pediatric surgical providers demonstrates wide disparity in the access to pediatric neurosurgical care across geographic and socioeconomic regions. An estimated 330 pediatric neurosurgeons work in LICs and lMICs, wherein more than 1.2 billion children reside, which translates to a ratio of 1 pediatric neurosurgeon per 3.6 million children. In contrast, in HICs and uMICs, there is roughly 1 pediatric neurosurgeon for every 370,000 children. As a result, the average patient in LICs and IMICs must travel a much greater distance to seek neurosurgical care. $.^{22} \mathrm{Be}-$ yond simply the distance required to seek a neurosurgeon, neurosurgeons themselves in many LMICs describe basic equipment needs, including drills and microscopes, which are essential for safe neurosurgical operations. Endoscopic skills and advanced management of epilepsy and vascular disorders in particular were described by surgeons across many regions and lower income groups as essential areas of training need. A tremendous desire exists among surgeons of all income groups and geographic regions to collaborate with one another in an effort to expand the quantity and quality of pediatric neurosurgical care worldwide.

While this effort represents the first of its kind describing pediatric neurosurgical care, the global disparity in access to healthcare-and surgical care in particular-is well known. In 2015, the Lancet Commission on Global Surgery revealed that 5 billion people lack access to safe and affordable surgical and anesthetic care, and that more than 140 million additional surgical procedures are needed each year in LMICs to prevent disability and death. ${ }^{18}$ Surgical disease has been described as "the neglected stepchild of global health," a label attributed in part to the international community's greater focus on communicable diseases such as tuberculosis and AIDS..$^{10}$ Additionally, the perception that delivery of adequate surgical care entails prohibitive human and material investments, and the relative lack of vocal surgeon advocates combine to create an ill-addressed problem.

The Lancet report covers all surgical specialties and references neurosurgery only peripherally: intracranial hematoma evacuation and hydrocephalus repair are mentioned as common procedures encountered in LMICs. ${ }^{18}$ In 2018, the Global Neurosurgery Initiative at the Program in Global Surgery and Social Change published an executive summary outlining the current capacity and deficit of neurosurgical care. ${ }^{8}$ According to this report, more than 5 million neurosurgical cases go unmet each year. Roughly 22,500 additional neurosurgeons need to be trained to meet this need, the majority of whom must be placed in LMICs where the neurosurgical deficit is greatest.

The proportion of this deficit that represents pediatric disease is unknown. Each year, there are nearly 400,000 new cases of infant hydrocephalus, ${ }^{9}$ and more than 950,000 operations are needed for children with hydrocephalus worldwide. ${ }^{8}$ An estimated 3 million children sustain a traumatic brain injury annually, of which an unknown proportion warrant the attention of a neurosurgical specialist. ${ }^{7}$ Epilepsy, a condition predominantly affecting children, has an estimated worldwide surgical burden of more than 1.4 million cases. ${ }^{8,23}$ The global volume of pediatric brain tumors, cerebrovascular anomalies, and se- 


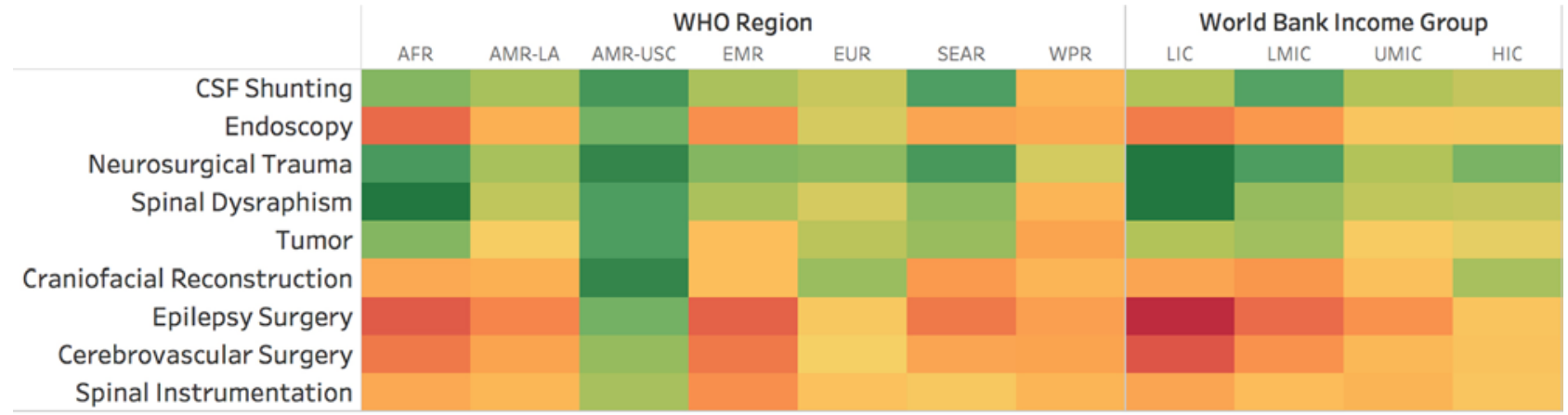

Percentage of respondents indicating training needs

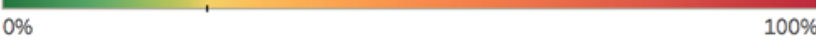

FIG. 4. Neurosurgical training needs worldwide. The heat matrix demonstrates the percentage of respondents who indicated a need for additional training in the specified skill or competency. Orange and red boxes signify a majority of respondents.

vere central nervous system infections add to the overall burden of pediatric neurosurgical disease. ${ }^{8,20}$ For comparison, in 2016 there were an estimated 160,000 new cases of HIV $^{14}$ and 1 million new cases of tuberculosis diagnosed in children. ${ }^{25}$

In developing countries, little attention is given to pediatric surgical disease. ${ }^{3}$ Most child health programs fail to address injuries, congenital abnormalities, and surgical infections, leading to significant childhood death and disability. ${ }^{1}$ This is despite the fact that pediatric surgery has been shown to be cost-effective in developing countries. ${ }^{21}$ In Uganda, for example, congenital hydrocephalus may be treated at a lifetime cost of US \$59-\$126 per disabilityadjusted life years averted..$^{24}$ The provision of antiretroviral drugs in sub-Saharan Africa, on the other hand, costs $\$ 500-\$ 600$ per disability-adjusted life years averted. ${ }^{15}$

Surgeon density is an important indicator of healthcare quality and access, and a shortage of specialists represents a significant reason for the unmet surgical need worldwide. ${ }^{13}$ Results from this survey suggest that a significant inadequacy in pediatric neurosurgical coverage exists, especially in Africa, the Middle East, and South-East Asia, with relative deficiencies also seen in many parts of Lat- in America and the Western Pacific. The source of this deficit is multifactorial. In LMICs, training programs are scarce or inaccessible. Existing programs are often insufficient to provide trainees with the knowledge and skillset to safely and effectively administer the breadth of pediatric neurosurgical care. ${ }^{13,16}$ Most LMICs harbor a higher proportion of children in the population than HICs, which further exacerbates the differential deficit among income groups. The majority of the pediatric surgery to be done is in LMICs, and most of the surgery to be done in these countries is pediatric. ${ }^{17}$ In addition, "brain drain" is a wellcharacterized phenomenon that aggravates the shortage of specialists where they are needed most. LMIC surgeons often seek opportunities in HICs where there may be higher economic gains, greater opportunities for career advancement, political stability, and more efficient healthcare systems. .,13,16 $^{1}$ Finally, surgeon maldistribution magnifies the problem. The overwhelming majority of LMIC respondents of this survey work in a tertiary or quaternary hospital. Chirdan and colleagues found that $90 \%$ of pediatric surgeons in Africa practice in major cities and none in rural areas, where two-thirds of the African population resides. ${ }^{5}$ Naturally, centralization of limited resources is

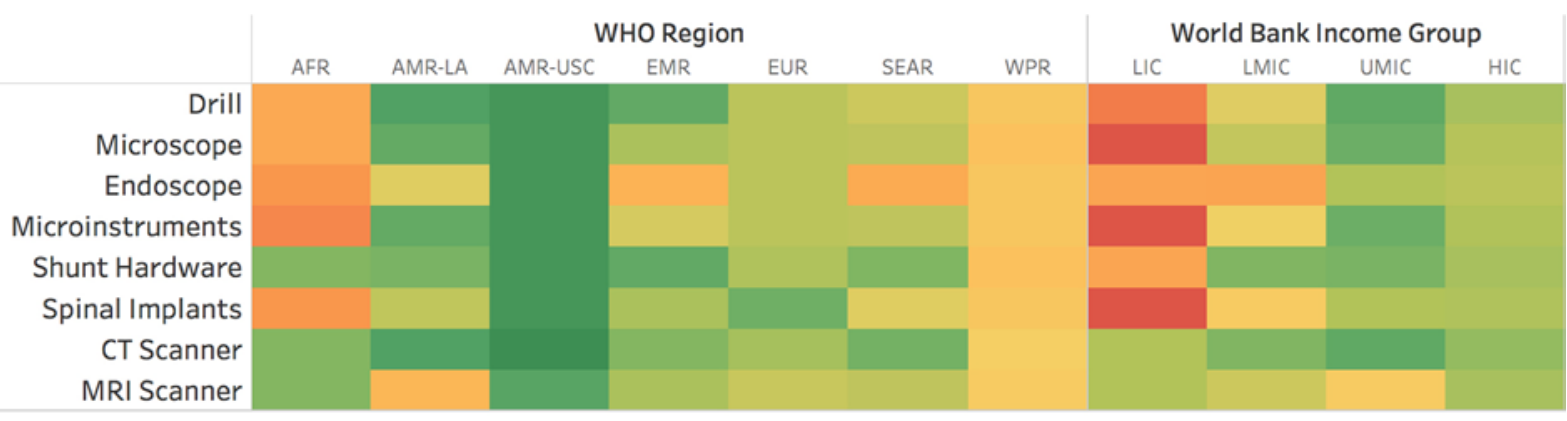

Percentage of respondents indicating equipment needs

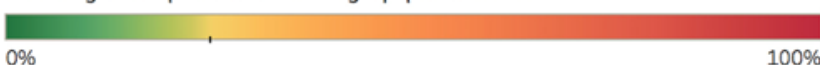

FIG. 5. Neurosurgical equipment needs worldwide. The heat matrix demonstrates the percentage of respondents who indicated a need for the specified equipment at their facility. Orange and red boxes signify a majority of respondents. 
an efficient way to deliver specialized services to a broader population. However, an organized referral system from primary to quaternary levels should exist, to allow timely and effective coordination of urgent and emergency care. ${ }^{1}$

To be certain, access to pediatric neurosurgical care is influenced by more than simply the presence of a pediatrics-trained neurosurgeon. Staffed hospitals and clinics, equipped and sterile operating theaters, blood-banking facilities, capable anesthesiologists, and services accessible and affordable to the at-risk populations are all fundamental to the provision of effective pediatric neurosurgical care. Societal and civic entities external to the healthcare sector-public transportation, welfare programs, education and awareness, geopolitical and geospatial forces ${ }^{6,22}-$ are also vital to equitable and far-reaching delivery of care. ${ }^{4}$ Task sharing is a viable, albeit controversial, reality in many healthcare networks in resource-limited settings. Many have argued for training nonneurosurgeons-even nonphysicians - to perform basic neurosurgical procedures in healthcare-impoverished regions as a less expensive means of providing emergency care when the alternative is often death. ${ }^{2}$ But others have strongly cautioned against this "anything is better than nothing" approach, urging a more earnest recognition and support by the international community of ongoing efforts to train competent neurosurgeons. ${ }^{11}$ Nonetheless, general pediatric surgeons reported that, on average, $14 \%$ of their practice involved the management of patients with neurosurgical conditions. Moreover, in most countries, general neurosurgeons (those not self-identifying as pediatric specialists) care for children in addition to their primary, adult practice. Indeed, nearly one-third (31\%) of their patient population was noted to be pediatric. Expanding the capacity of pediatric neurosurgery worldwide will likely involve both training more pediatric neurosurgical subspecialists and expanding and enhancing the pediatric armamentarium of adult neurosurgeons.

The observation that relatively few respondents from LICs and IMICs reported equipment need for an MRI or CT scanner is curious, as intuition might suggest that many facilities in these settings lack such commodities. A possible explanation may be that respondents operate in large, national referral hospitals that possess the few such scanners in the country. Alternatively, the respondents' answers may reflect a situation of relevancy: a facility that lacks a reliable craniotome or microinstruments may not count an MRI unit among its primary equipment needs.

The findings presented above warrant interpretation in light of several important considerations. As with all surveys, the results provided herein reflect self-reported experience and perception. Results related to proximity of care, equipment and training needs, and adequacy of neurosurgical coverage all assumed that local neurosurgeons were familiar with these data and represented a reliable means of obtaining it. Without baseline data to compare against, it is challenging to know how reliable this assumption may be. Alternative strategies include worldwide, country-specific data collection campaigns via Ministries of Health or nongovernmental agencies. While necessary, such efforts are time intensive and costly, and may themselves yield results not necessarily reflective of real time, on-the-ground resources and needs. Nonetheless, if pediatric neurosurgery is to make its way into the National Surgical Plan of LMICs, data from this or other survey efforts are crucial in establishing priorities. While an effort was made to capture a global representation of respondents, many countries were not represented and thus data were modeled using information from neighboring countries with similar geopolitical and economic characteristics. In addition, we were unable to calculate a survey response rate, as there was no reliable way of determining how many individuals were sent a survey link; few surgical societies were able to provide a membership census.

\section{Conclusions}

This survey of surgical providers demonstrates tremendous inequality in the access to and provision of pediatric neurosurgical care globally. Universally among LICs and lMICs, surgeons describe deficient provider coverage, longer travel times for patients, and basic equipment and training needs. Across all income groups and geographic regions, pediatric neurosurgeons express an interest in cross-collaboration for the purpose of expanding the surgical workforce globally and enhancing the quality of care delivered.

\section{Acknowledgments}

REDcap use and management for collection of data was funded by Institute for Clinical and Translational Research/NIH grant support (grant no. UL1 TR000445).

\section{References}

1. Bickler SW, Rode H: Surgical services for children in developing countries. Bull World Health Organ 80:829-835, 2002

2. Burton A: Training non-physicians as neurosurgeons in subSaharan Africa. Lancet Neurol 16:684-685, 2017

3. Butler EK, Tran TM, Fuller AT, Brammell A, Vissoci JR, de Andrade L, et al: Quantifying the pediatric surgical need in Uganda: results of a nationwide cross-sectional, household survey. Pediatr Surg Int 32:1075-1085, 2016

4. Butler EK, Tran TM, Nagarajan N, Canner J, Fuller AT, Kushner A, et al: Epidemiology of pediatric surgical needs in low-income countries. PLoS One 12:e0170968, 2017

5. Chirdan LB, Ameh EA, Abantanga FA, Sidler D, Elhalaby EA: Challenges of training and delivery of pediatric surgical services in Africa. J Pediatr Surg 45:610-618, 2010

6. Dempsey KE, Qureshi MM, Ondoma SM, Dempsey RJ: Effect of geopolitical forces on neurosurgical training in SubSaharan Africa. World Neurosurg 101:196-202, 2017

7. Dewan MC, Mummareddy N, Wellons JC III, Bonfield CM: Epidemiology of global pediatric traumatic brain injury: qualitative review. World Neurosurg 91:497-509, 509.e1, 2016

8. Dewan MC, Rattani A, Fieggen G, Arraez MA, Servadei F, Boop FA, et al: Global neurosurgery: the current capacity and deficit in the provision of essential neurosurgical care. Executive Summary of the Global Neurosurgery Initiative at the Program in Global Surgery and Social Change. J Neurosurg [epub ahead of print April 27, 2018. DOI: 10.3171/2017.11. JNS171500]

9. Dewan MC, Rattani A, Mekary R, Glancz LJ, Yunusa I, Baticulon RE, et al: Global hydrocephalus epidemiology and incidence: systematic review and meta-analysis. J Neurosurg [epub ahead of print April 27, 2018. DOI: 10.3171/2017.10. JNS17439] 
10. Farmer PE, Kim JY: Surgery and global health: a view from beyond the OR. World J Surg 32:533-536, 2008

11. Figaji A, Taylor A, Mahmud MR, Bello S, Wegoye E, Ssenyonga P, et al: On progress in Africa, by African experts. Lancet Neurol 17:114, 2018

12. Harris PA, Taylor R, Thielke R, Payne J, Gonzalez N, Conde JG: Research electronic data capture (REDCap) - a metadata-driven methodology and workflow process for providing translational research informatics support. J Biomed Inform 42:377-381, 2009

13. Hoyler M, Finlayson SRG, McClain CD, Meara JG, Hagander L: Shortage of doctors, shortage of data: a review of the global surgery, obstetrics, and anesthesia workforce literature. World J Surg 38:269-280, 2014

14. Joint United Nations Programme on HIV/AIDS: Global HIV \& AIDS statistics - 2018 fact sheet. UNAIDS.org (http:// www.unaids.org/en/resources/fact-sheet) [Accessed August 8, 2018]

15. Kahn JG, Marseille EA, Bennett R, Williams BG, Granich R: Cost-effectiveness of antiretroviral therapy for prevention. Curr HIV Res 9:405-415, 2011

16. Krishnaswami S, Nwomeh BC, Ameh EA: The pediatric surgery workforce in low- and middle-income countries: problems and priorities. Semin Pediatr Surg 25:32-42, 2016

17. Lalchandani P, Dunn JCY: Global comparison of pediatric surgery workforce and training. J Pediatr Surg 50:11801183,2015

18. Meara JG, Leather AJM, Hagander L, Alkire BC, Alonso N, Ameh EA, et al: Global Surgery 2030: evidence and solutions for achieving health, welfare, and economic development. Lancet 386:569-624, 2015

19. Park KB, Johnson WD, Dempsey RJ: Global neurosurgery: the unmet need. World Neurosurg 88:32-35, 2016

20. Robertson FC, Lepard JR, Mekary R, Davis MC, Yunusa I, Gormley WB, et al: Epidemiology of central nervous system infectious diseases: a meta-analysis and systematic review with implications for neurosurgeons worldwide. J Neurosurg [epub ahead of print June 15, 2018. DOI: 10.3171/2017.10. JNS17359]

21. Sitkin NA, Farmer DL: Congenital anomalies in the context of global surgery. Semin Pediatr Surg 25:15-18, 2016

22. Smith ER, Vissoci JRN, Rocha TAH, Tran TM, Fuller AT, Butler EK, et al: Geospatial analysis of unmet pediatric surgical need in Uganda. J Pediatr Surg 52:1691-1698, 2017
23. Vaughan KA, Ramos CL, Buch VP, Mekary RA, Amundson JR, Shah M, et al: An estimation of global volume of surgically treatable epilepsy based on a systematic review and meta-analysis of epilepsy. J Neurosurg [in press], 2018

24. Warf BC, Alkire BC, Bhai S, Hughes C, Schiff SJ, Vincent JR, et al: Costs and benefits of neurosurgical intervention for infant hydrocephalus in sub-Saharan Africa. J Neurosurg Pediatr 8:509-521, 2011

25. World Health Organization: Childhood TB. WHO. (http:// www.who.int/tb/areas-of-work/children/en/) [Accessed August 8,2018$]$

\section{Disclosures}

The authors report no conflict of interest concerning the materials or methods used in this study or the findings specified in this paper.

\section{Author Contributions}

Conception and design: Dewan, Harkness. Acquisition of data: Dewan. Analysis and interpretation of data: all authors. Drafting the article: Dewan. Critically revising the article: all authors. Reviewed submitted version of manuscript: all authors. Approved the final version of the manuscript on behalf of all authors: Dewan. Statistical analysis: Dewan, Baticulon. Administrative/ technical/material support: Baticulon, Rattani, Harkness.

\section{Supplemental Information}

Online-Only Content

Supplemental material is available online.

Tables S1 and S2 and Supplement. https://thejns.org/doi/suppl/ 10.3171/2018.7.FOCUS18272.

\section{Correspondence}

Michael C. Dewan: Vanderbilt Medical Center, Nashville, TN. michael.dewan@vumc.org. 